\title{
Research on Teaching Quality Monitoring System of Management By Objectives
}

\author{
Ming Fang \\ University Office \\ Xi'an Shiyou University \\ Xi'an, Shaanxi, China \\ mfang@xsyu.edu.cn \\ Wei Wu \\ Academic Affairs Division \\ Xi'an Shiyou University \\ Xi'an, Shaanxi, China \\ wuwei@xsyu.edu.cn
}

\author{
Jing Luo \\ Higher Education Institute \\ Xi'an Shiyou University \\ Xi'an, Shaanxi, China \\ luojing@xsyu.edu.cn \\ Kaiyuan Meng \\ Academic Affairs Division \\ Xi'an Shiyou University \\ Xi'an, Shaanxi, China \\ kymeng@xsyu.edu.cn
}

\author{
Yongxin Liu \\ Higher Education Institute \\ Xi'an Shiyou University \\ Xi'an, Shaanxi, China \\ 1liuyongxin@163.com
}

\begin{abstract}
TQMS plays a more and more important role in assuring the effect of universities education. Researching the current system from the theoretical and practical aspects found that the systems exists some problems, it is difficult to meet the teaching quality assurance need of the connotation-oriented development stage of universities. Through researching, constructing TQMS of management by objectives has theory and practice feasibility. The new TQMS is designed with some ideas of management by objectives; it should include three work systems to achieve the teaching objectives: institutional improvement, standardized work, support system. Last, we propose some suggestions for possible problems in designing process.
\end{abstract}

Keywords-component; teaching quality monitoring system of management by objectives; management by objectives; support system

\section{INTRODUCTION}

With higher education entering the stage of the Connotation-oriented development in China, it has been put forward higher quality requirements for college students, But our teaching quality management methods and tools are still lagging behind the demand. TQMS (Teaching Quality Monitoring System) is the main measure of many universities in teaching quality management, but in the actual construction, the system exists of unscientific nature in the concept, content and other aspects, which needs construct from a new perspective on teaching quality monitoring system.

\section{CONSTRUCTION OF TQMS STATUS}

Many universities have had constructed TQMS or teaching quality management practices more or less, through research the literature and practice of the status found that the TQMS involves in the following questions:

\section{A. TQMS Emphasis Excessively on Control, which Makes it} Operation Undesirability.

Many scholars and university administrators treat TQMS as teaching management measures, resulting in the system paying more attention on the rule proper and timely implementation, neglect of the effect and the aim of the rules implementation. TQMS treated as teaching management measures, which makes monitoring turning to control. This TQMS exacerbates conflict between teaching management personnel, teachers and teaching management system, deviated from the aim of the TQMS. This TQMS dampens the work enthusiasm of grass-roots teaching staff, loses their recognition and support, it makes TQMS lack of basis for long-term operation.

\section{B. The Connotation of TQMS is not Comprehensive Enough.}

Many universities' TQMS includes many aspects of teaching work; they emphasized on building the evaluation system, lack the necessary support and service system. Many universities develop the teaching system, allocate funds, and then propose the indicators to teaching work, but lack necessary knowledge and skills support and help for the teachers, which makes the indicators and the corresponding of standards lacks of faculty recognition. As a complete teaching quality monitoring system should not only focus on indicator system of science, but also concern about the appropriate support and service system completeness. Just attach importance to the achievement of the indicator, it maybe damage the quality of teaching culture, making monitor system just for monitoring, lack of incentive-oriented indicators can't achieve the quality of teaching continuous improvement. 
c. The Indicator of TQMS Lacks of Objective-Oriented, the Emphasis is not Obvious.

TQMS As the system of evaluation and regulation the teaching quality of school, it should be adapted for our educational goals and the indicators should reflect its characteristics and priorities. At present, many universities indicator system copy from their original teaching management approach, or apply directly other universities indicators system, this behavior results that the systems between different schools teaching quality monitoring indicator system looks the same. And another, some indicators have only standardizing the teaching order, system implementation, and monitoring of teaching activities to ensure teaching action smooth, excessive emphasis on order implementation reduce the creative energy of the faculty, discipline and motivation lost the effect.

\section{The other Data Collection and Processing Systems which Supports TQMS Running are Imperfect.}

TQMS plays an important role in the data collection in universities, but it can not be the only source of information collection. At present, many universities take the TQMS as only activity to collect information, during the assessment, the short-term assault-style data collection will increase the workload of teaching units, the quality of the data is often not optimistic. For example, the daily work of data collection lacks of teaching faculty supervision, so that when assessing begins, the faculty of units may fabricate data. In addition, data processing is not enough, the academic committees of many universities are responsible for fewer teaching data processing, the reason is that inadequate staff and the structure of staff is irrational and so on. For example, teaching interim inspection work, outstanding teachers or teaching activities such as teacher assessment data collected, that often only to be assessed, did not go into teaching problems reflected in the data. The processing is relatively simple, so that there are no more feedback effects.

\section{THEORETICAL ANALYSIS THE TQMS CONSTRUCTING WITH MANAGEMENT BY OBJECTIVES}

Manage by Objectives theory had been used successfully in business management, it has some accord with teaching quality management. Its management philosophy can draw up to university teaching quality management.

Peter F. Drucker said "The objectives should therefore be set by fixing one's sight the desirable. Only then should the question be raised what concessions to the possible have to be made. "[1] Managers have five basic tasks: a) managers need to set objectives and explain it to people that has relationship with objectives achieved in order to effectively achieve the objectives; b) Management personnel should organize and analysis the business, get their relationships, Classify Work, and manage work. Then combination of these units and operations become an organizational structure, selection personnel and implementation of management units; $c$ ) motivation and communication work; $d$ ) measure the importance of the work, and determine the criteria of analysis the work performance, evaluation and interpretation; $e$ ) improve human resource. [2] Management by Objectives organizes the work structure by objectives, and evaluation work, training personal and motivation to ensure objectives achieved. Combing the theory, it has many meeting points with teaching quality production process.

First, achievement teaching objectives requires various departments of universities to cooperate, all departments function effectively. Teaching objectives as a guide to set up teaching quality monitoring system, design indicators and assess, regulate, control and motivate teaching activities. Second, teaching is a professional process. Need to improve human capital of staff and students. Third, what kind of work has important influence to the objectives achieving. Those work should propose quality standards, evaluate, control and feedback, timely adjustment, to gradually improve the teaching quality. From the perspective management by objectives to establish TQMS has theoretical and practical feasibility.

\section{CONSTRUCTION OF TQMS BASED ON MANAGEMENT By OBJECTIVES}

\section{A. Teaching Objectives and Corresponding Indicators of $T Q M S$}

Quality of teaching objectives should be clear written expression, such statements should get consensus by all university staff. Such as Purdue University training objectives identified as "Cultivate outstanding talents, a global impact" and therefore on education, they put more to train students' global innovation and collaboration capabilities. [3] Consensus objectives in favor of multiple departments work coordination, joint action to achieve their objectives. According to the theory of management by objectives, work should be adjusted and organized by objectives. We analyze the character of work, classify, set the minimum requirements, and establish a complete TQMS of management by objectives.

The work can be divided into three types: support work, Standardized work, institutional improvement; they can be seen easily in the universities. The support work is the organization and activities that can improve the teaching skills, and improve the level of management of staff, help students to learn better training such as learning consulting services and other work. Standardized work is about teaching procedural complying and the work order enforcement. Institutional improvement is the work conducive to teachers and staff efficient.

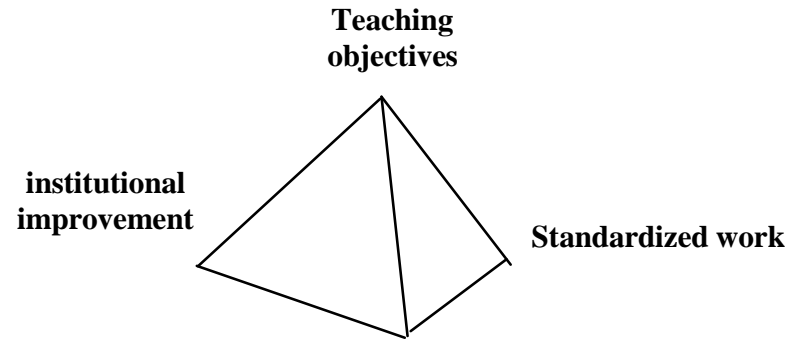

support system

Figure 1. Teaching quality monitoring system of management by objectives

Figure I, the objectives of teaching work generally can be divided into three types, internal of the three pyramids include 
some hidden teaching quality culture. Set specific indictors for three types of work, and based on long experience in teaching data retrieval and determine the appropriate standard of work, and thus construct the object-oriented teaching quality monitoring indicator system of management by objectives.

\section{B. Support System for TQMS of Management by Objectives}

The aim Constructing TQSM of management by objectives is to promote teaching quality improvement, but first, it is necessary to improve teaching skills and student learning effect, we must provide some support and help for them. What kind of objectives, so the way of work would be done. From this logic, TQMS should include two aspects at least: First, the administrative management system. This system includes monitoring implementation of teaching management rules; Second, the support system. Some scholars have proposed providing the necessary hardware and other support for teaching, such as the Academic Affairs Division, logistics, student services offices, but more importantly, should provide support for teaching and learning. For example: Purdue University in order to enhance the teaching ability of teachers and to content students' educational needs establishment a lot of support and service organizations.[3] Teaching is the professional activity, not because he is a teacher, he can teach, he need continuous learning, communication ,then he maybe become better teachers., so is the students. Besides classroom teaching does not provide students with adequate learning support. The support system makes the evaluation criteria having the logic foundation; so that teachers approve teaching management objectives, they will know where they can get help to achieve the objective. Maybe we can build professional development of teachers teaching and research center or other forms organization.

\section{TQMS of Management by Objectives Operation and Corresponding Running Regime Institutions}

TQMS of management by objectives is to evaluate, support and service system, is a professional work, quality assurance as a new teaching quality approaches need strong support from the school, it should carry out the functions by the appropriate organizations and institutions. Fixed operating agencies help clarify responsibilities, continuous improvement of TQMS of management by objectives. We can establish a permanent independent body to lead by the teaching principals. Independent operating agencies are helpful assessing the objectivity and authority. But the monitoring system can not be in charge of the Academic Affairs Division, because it can't e implement of teaching work agency to evaluate their teaching Registry Services Job. The teaching principals should chair TQMS of management by objectives, the other staff can come from the academic committee or teaching supervisory staff, the non-fixed personnel to operate the quality of teaching evaluation and feedback work. Teaching quality monitoring work of Faculties should be charged by the teaching dean, he should monitor faculty teaching and take the self-evaluation report to university TQMS, timely diagnosis and regulate teaching. In short, the two levels TQMS institutions need to develop fair and reasonable operation system in order to ensure the continued monitoring work carried out.

\section{THE PROBlems NeEd tO PAY IN CONSTRUCTION TQMS OF MANAGEMENT BY OBJECTIVES}

\section{A. Nurturing the Teaching Quality Culture Conducive to Enhance the Teaching Quality}

Teaching Quality is the lifeline of the school, which is the most important condition that determines the schools existence. Teaching quality culture helps to improve the quality awareness of all teachers, through joint efforts to improve the quality of teaching continuously. [4] Although TQMS promotes the teaching quality to a certain extent, but the good quality culture plays a greater role in improving TQMS effect. Shown in Figure 1, the right quality culture should be within the quality management system. Nurturing good teaching quality culture requires effective measures. Such as: implementing TQMS should pay attention to communication top-down and bottom-up, so that teaching staff unify awareness of the work value; also through variety of incentive programs guide teachers to know good relationship between good teaching and students' academic, to stimulate the honor of their work.

\section{B. Balancing with Other Teaching Activities}

University teaching is multifaceted and multi-layered. TQMS of management by objectives has great guidance and regulation, which in turn has limited some innovative behavior. There may exist work which are not suitable for TQMS of management by objectives, in order to protect work enthusiasm of these work-related staff, it needs to set other incentives and guidance measures to balance work. For example, the new major and new courses are often at the exploratory stage, it is not suitable for TQMS evaluation.

\section{Protecting Motivation of Staff are Assessed by the TQMS}

When the TQMS of management by objectives is in the developed process, some projects are likely to affect teachers' work enthusiasm, these projects should be designed selectively, or choose other assessment indicators. For example, teachers' job evaluation even how scientific approach to the evaluation design will cause discontent in varying degrees, so these projects lead to teachers in self-evaluation, to achieve the purpose of self-learning and improving

In addition, the projects concern to the students assessment results should feedback to the students timely, their legitimate educational needs should safeguards from the resources and the system, so that students feel respect for the views of individual.

In short, the TQMS of management by objectives as a new perspective guide and control teaching, trying to change the shortage of old monitor system. In the system of designing and operation stage, requires lots of support from universities. Especially, the education aims, the purpose of monitoring systems should be widely publicized, so that management staff and teachers are aware of their work value for the school aim. Through modify continuously the TQMS of management by objectives, really promotion university education to a new level.

\section{REFERENCES}

[1] Peter F. Drucker, The Practice of Management. Qi Ruolan Trans. Beijing: Mechanical Industry Press, 2006, pp.37. 
[2] Peter F. Drucker, Management: Task, Resopnsibilities, Practices. Wang Yonggui trans, Beijing: Mechanical Industry Press,2009, pp.25-26.

[3] Qie Haixia, Wang Shibin. Analysis on the Engineering Teaching Quality Guarantee System in American First-class Universities. Higher Education of Engineering, 2013,vol.1 ,pp.139-146.
[4] Zhang Zhonghua, Chen lin, Creating Culture of Quality Teaching, Waking Teachers Educating Passion. China Higher Education, 2010, vol.1,pp.42-44 